\title{
Connections and interlocations between self-image, self-esteem, active sexuality, and quality of life in ageing
}

\author{
Conexões e interlocuções entre autoimagem, autoestima, sexualidade ativa e qualidade de vida no envelhecimento
}

Conexiones e interlocaciones entre autoimagen, autoestima, sexualidad activa y calidad de vida en el envejecimiento

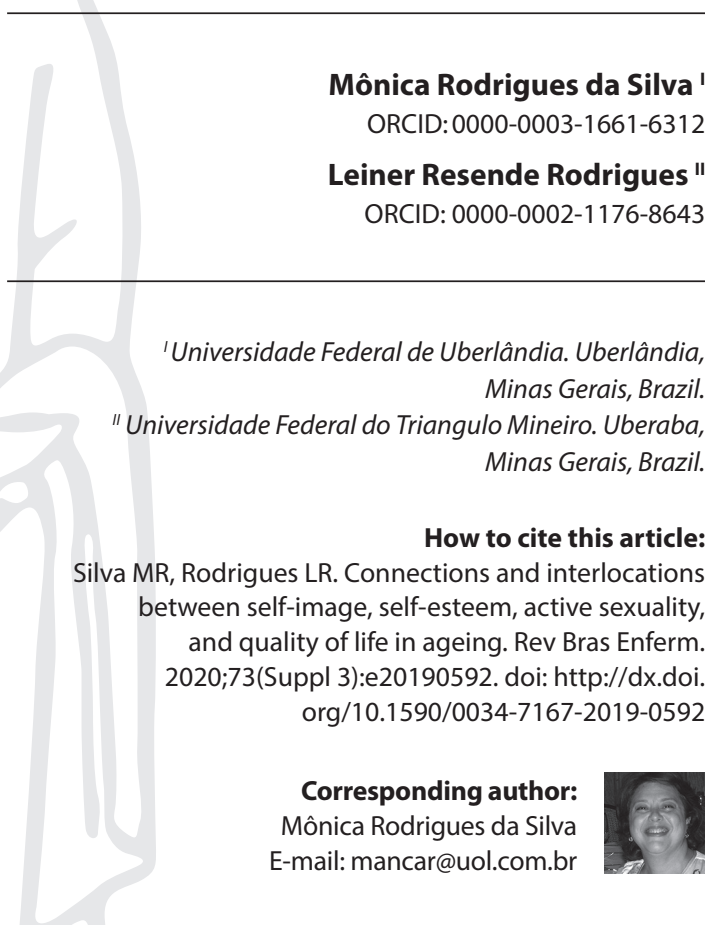

EDITOR IN CHIEF: Antonio José de Almeida Filho ASSOCIATE EDITOR: Hugo Fernandes

Submission: 11-01-2019

Approval: 06-09-2020

\begin{abstract}
Objective: to reflect on the connection between self-image, self-esteem, active sexuality, and quality of life in ageing; identify which measurement instruments in Brazilian and international literature interconnectively address the connections referred to in the general objective. Method: a theoretical-reflexive essay. Results: the reflection was described in the guiding axes: Connections between self-image, self-esteem, active sexuality, and quality of life in ageing; Interlocutions and instruments for measuring the connection between sexuality and ageing. Instruments in Brazilian and international literature are unable to address this topic in an interconnected way. Limitations and disadvantages of application with elderly individuals are presented. Final considerations: carrying out qualitative research and validating quantitative instruments that show connections and interlocutions, without stigmas and reprimands, common in this age group, should be encouraged in the scientific field and in social spaces.

Descriptors: Sexuality; Aged; Questionnaires; Self-Esteem; Self Concept.
\end{abstract}

\section{RESUMO}

Objetivo: refletir sobre a conexão entre autoimagem, autoestima, sexualidade ativa e qualidade de vida no envelhecimento; e quais os instrumentos de mensuração encontrados na literatura brasileira e internacional, que abordam de forma interligada as conexões referidas no objetivo geral. Método: ensaio teórico-reflexivo. Resultados: a reflexão foi descrita nos eixos condutores: Conexões entre autoimagem, autoestima, sexualidade ativa e qualidade de vida no envelhecimento; Interlocuções e instrumentos de mensuração da conexão entre sexualidade e envelhecimento. Instrumentos na literatura brasileira e internacional não conseguem abordar de forma interligada a referida temática. Apresentam-se limitações e desvantagens de aplicação com idosos. Considerações finais: a realização de pesquisas qualitativas e a validação de instrumentos quantitativos que evidenciem as conexões e interlocuções, sem estigmas e repreensões, comuns nessa faixa etária, deve ser estimulada no campo científico e nos espaços sociais.

Descritores: Sexualidade; Idoso; Questionários; Autoestima; Autoimagem.

\section{RESUMEN}

Objetivo: reflexionar sobre la conexión entre la autoimagen, la autoestima, la sexualidad activa y la calidad de vida en el envejecimiento; y qué instrumentos de medición se encuentran en la literatura brasileña e internacional, que abordan de manera interconectada las conexiones mencionadas en el objetivo general. Método: ensayo teórico-reflexivo. Resultados: la reflexión se describió en los ejes rectores: conexiones entre la autoimagen, la autoestima, la sexualidad activa y la calidad de vida en el envejecimiento; Interlocuciones e instrumentos para medir la conexión entre sexualidad y envejecimiento. Los instrumentos de la literatura brasileña e internacional no pueden abordar este tema de manera interconectada. Existen limitaciones y desventajas de la aplicación con los ancianos. Consideraciones finales: la realización de investigaciones cualitativas y la validación de instrumentos cuantitativos que muestren las conexiones e interlocuciones, sin estigmas y amonestaciones, comunes en este grupo de edad, deben fomentarse en el campo científico y en los espacios sociales. Descriptores: Sexualidad; Anciano; Cuestionarios; Autoestima; Autoimagen. 


\section{INTRODUCTION}

\section{State Of The Art}

Constant social and epidemiological changes in Brazil require health professionals to continually think about strategies that enable answers to the demands of care that arise in the most different care settings. Looking specifically at the healthcare of the elderly population, through social and demographic indicators, the country's age structure is changing. The elderly group is today an expressive population contingent in absolute terms and of increasing relative importance in the whole of Brazilian society. Thus, there are a series of new demands and demands in terms of public health policies and active insertion of elderly individuals in social life ${ }^{(1)}$.

Ageing involves multiple dimensions that give the phenomenon a complex character, whose attempt to understand from a single perspective makes its understanding fragmented. It is inevitable not to imagine the ageing body associated with stigmas and prejudices such as the appearance of diseases; physical limitations; need for care and social support; interruption of social relationships; and restriction in social roles and cognitive specialization ${ }^{(2)}$.

Despite ageing being part of human development and the fact that the Brazilian population is increasingly composed of many elderly people, it is observed that the topics related to old age, in investigative terms in the country, are still considered recent, mainly from the point of view scientific and social ${ }^{(1)}$.

It is worth mentioning that ageing is an individual process, where each person experiences common situations, but with different ways of dealing. Elderly who age well are who successfully adapt to a variety of expected and unexpected stressors. Stressors inherent in life, situations, feelings and the full range of experiences. This successful adaptation is linked to your own assessments of your general health. In addition to properly considering the disease, elderly individuals also take into account their subjective perception ${ }^{(3)}$.

It is necessary to seek a new understanding of ageing, as the vast majority of people do not prepare for this moment. Socially, there is a desire to live for many years, but there is no desire to age ${ }^{(4)}$.

Old age consists in the fact that it is not a state, but a constant and always unfinished process of subjectification. It can be said that most of the time there is not an ageing being, but an ageing being. This concept brings us closer to one of the newest terms used to define the ageing process, the concept of "getting on in years". It is a popular term, defined as an adult preparation for old age, just as adolescence is a preparation for adulthood. The individual getting on in year experiences the stages of ageing ${ }^{(1)}$.

Approaching ageing from different angles and also with new studies shows the prejudice against old age. Such prejudice occurs in different spaces and in different ways. The lack of knowledge about the issues surrounding getting on in years in the cultural approach highlights stereotypes and perceptions of themselves and others about them and about what stands out as the roles of elderly individuals $s^{(4)}$.

The first experience of old age takes place in the body and in the look itself. When looking in the mirror, old age reveals itself, causes fear and astonishment ${ }^{(3)}$.

The body itself does not reveal old age as an attribute, but once it starts to be stigmatized, it settles in the body, causing anxiety in individuals who age. A stigmatizing and prejudiced assessment is the reason for abomination of individuals who age before their own body. Thus, it is essential to examine the particular means of how this happens in different societies, including the role of images on body perceptions and the way in which constructing identity depends on this perception ${ }^{(4)}$.

The concept of body image can be defined as someone's psychological experience about the appearance and functioning of their body ${ }^{(2)}$. It is the way in which our body appears to ourselves, corresponding to our mental representation of the body itself. Seeing ageing through the eyes of the ageing person is a way of seeing, considering the individual aspects and thus understanding that there are different ways of seeing old age and the process of leading it. Many elderly people reject their own ageing due to the image they make of themselves, developing a feeling of self-depreciation and low self-esteem, with a great impact on their quality of life ${ }^{(3)}$.

The passage of time, in many human experiences, is experienced with bewilderment. Individuals do not recognize in themselves the metamorphoses arising, step by step, with senescence or getting on in years; they recognize them in the other; it is the other that ages. But, surprisingly, no more than suddenly, they see their old age in the eyes of the other, who, like a mirror, returns those "foreigners" to whom they have become ${ }^{(3)}$.

The old body no longer has the aesthetically standardized beauty of the young body, but it has a mature experience of emotions. For this reason, old age must be a time of maturity and participation. If this does not happen, they tend not to accept challenges, not to offer reactions, inevitably leading to a decrease in the opportunity for behavioral changes and acquisition of attitudes more consistent with the socio-cultural environment ${ }^{(4)}$.

From this perspective, the potentiating effects of experiences and among them sexual ones are also recognized. Sexuality can be understood as one of the activities that most contribute positively to quality of life, but it represents something that is unique and almost exclusive to healthy and physically attractive young people. If there are difficulties in addressing ageing mainly because of its ambiguities, various discourses, consensus and disagreements, addressing sexuality in ageing, it becomes even more challenging ${ }^{(4)}$.

This study is based on that considering the review of readings on ageing, self-image, self-esteem, active sexuality, and quality of life. There is a clear lack of studies that draw a dialogue between these aspects and specifically to the sexually active "getting-on-in-year individual".

\section{OBJECTIVES}

To reflect on the connection between self-image, self-esteem, active sexuality, and quality of life in ageing; and identify the measurement instruments in Brazilian and international literature that interconnectively address the connections referred to in the general objective.

\section{METHOD}

This is a reflective theoretical essay originated from studies and discussions pertinent to the Graduate Program in Health Care, Doctorate level, at Universidade Federal do Triângulo Mineiro; from participation in the courses taken and research groups; starting in January 2017 until May 2019. 
The reflections proposed here were derived from a theoreticalpractical basis in the light of national and international literature, pertinent to the topic and the experience of the authors in practice, teaching and research in the health of the elderly population and mental health.

The study conducted by Viscardi and Correia ${ }^{(2)}$ caused concern. Bibliographic research was carried out on the Virtual Health Library (VHL) databases; in Health Science information sources in general composed of LILACS (Latin American \& Caribbean Literature in Health Sciences) and SciELO. This search aimed to identify the main international and Brazilian questionnaires to assess self-esteem, self-image, active sexuality, and quality of life in ageing and to verify the connections and interlocutions and aspects of cultural validity of these variables. There are several instruments designed to assess variables in isolation or the relationship between up to three in different populations, which are referenced in different concepts, empirical bases and theoretical frameworks. More than identifying existing instruments, one should reflect which ones are the most used and which present the best suitability for use with elderly individuals, in addition to highlighting those that provide more subsidies that meet the singularity of that population.

For presentation of ideas, conjectures and reflections, two conducting axes are woven; one to make the investigation of conjectures and reflections feasible, designing the study setting; and the other to present the results of this investigation. Such axes are conductors of interpretations and reflective impressions guided by the understanding of the topic in Brazil and in the world, in its different cultural and social contexts, directed to the Brazilian reality.

As it is not a direct application research, with people and personal documents, the need to submit the study for ethics committee assessment was excluded.

\section{RESULTS}

\section{Connections between self-image, self-esteem, active sexuality, and quality of life in ageing}

Research conducted with elderly individuals have demonstrated the relationship between self-esteem and self-image with complaints about impaired memory ${ }^{(5)}$. It is noteworthy that satisfaction with self-image can interfere, directly or indirectly, in maintaining a healthy and active lifestyle, affecting health care actions, favoring quality of life (QoL). With regard to complaints related to memory, so frequent in the elderly, they should be investigated with a focus on related factors. They represent a reason for dissatisfaction with their abilities, which can negatively influence well-being and Qo $L^{(5)}$.

QoL also encompasses the domain of individual perception of sexuality, a complex variable due to its multidimensionality. It can be expressed from the interaction with oneself and with the other and manifesting itself in social relationships through corporeality ${ }^{(6)}$.

Bearing this in mind, sexuality can and should be distinguished from the sexual act that portrays only one of the forms of expression of human love.

Ageing, followed by changes in the body, physiological or aesthetic, in addition to prejudice, stereotypes, faces the culture of asexuality, with the possibility of repression of desires and the sexual act. With a direct impact on social relations, for a positive sexuality, it is necessary to recognize and value sexual experiences lived with satisfaction. Nursing literature shows the correlation of self-esteem with the results of life, implicitly among them human relationships, work, health, sexuality, and healthy ageing ${ }^{(7)}$.

It can be said, in relation to the phenomenon of sexuality in ageing, that the analyzes developed on the subject are still scarce. Especially regarding the sexuality of subjects over the age of 65 . The study of sexuality in old age presents some problems. One of them is the Cohort effect, where older people grew up in less permissive times and are not used to talking about sexual issues. In research with studies of sexual activity in old age, it was observed that the more recent, the more frequently in these studies people admit to having sex. It is evident that older groups can provide more barriers and less information, because they are unwilling to talk about it ${ }^{(5)}$. This behavior reinforces the presence of a study niche to be deepened. Most of the existing studies address issues of dysfunction and changes in the sexual functioning of men and women. They focus on negative physiological aspects, bringing few reflections on how elderly individuals have dealt emotionally with their sexuality ${ }^{(7)}$.

There is a change in sexual response, qualitatively and quantitatively, with advancing age; and they do not dissociate themselves from the general context of other organic forces also altered by time, such as locomotion, digestion and circulation. The organism, as a whole, changes over time and within the context of sexuality, it also changes, but it does not become less pleasurable or pleasant. There is a constitution of multiple sexual life, being woven by elements such as affection, complicity, intimacy, the sexual act itself, among others ${ }^{(8)}$.

Sexuality is influenced by moral codes, values, beliefs and policies peculiar to each culture and depends, fundamentally, on the attitude that each person adopts towards life. In this perspective, the potentializing effects of sexual experiences are recognized. Sexuality can be understood as an activity that contributes positively to the QoL of elderly individuals. And, when so understood, it appears as something unlimited, a complex process that includes emotions and behaviors that are not reduced to just sexual relations ${ }^{(7)}$.

Sexual satisfaction, added to self-esteem, shows a direct improvement in sexual, physical and mental health ${ }^{(1)}$. Health education actions can be relevant strategies for, through the inclusion of information and instructions, experiencing this moment positively, combining self-knowledge and self-confidence.

Self-esteem and self-image are understood as fundamental aspects of the lives of elderly individuals; they are interconnected and dependent on each other, directly influencing their QoL. They reflect social roles occupied by the individual and which are always changing as new experiences are acquired in daily life ${ }^{(8)}$.

Self-image, or perception of body image, is the representation that each person has of his or her body, formed in his or her mind, or the way in which the body presents itself to each person. Body image is someone's experience of the appearance and functioning of their body, the way in which our body appears to ourselves, being our mental representation ${ }^{(2)}$.

Self-esteem, in turn, is the attitude and feeling that individuals have towards themselves. It can also be interpreted as being the feeling, the appreciation and the consideration that they feel for themselves; how much they like themselves; how they see themselves; and what they think about themselves. It covers diverse feelings, such as competence and personal value, adding 
to those of self-respect and self-confidence, and thus reflects our ability to deal with life's challenges and influences differently the way elderly individuals perceive and experience their ageing and corporeality ${ }^{(2)}$.

Unconsciously, people are conditioned to believe and reproduce, as truths, that their appearance and body are no longer attractive. Self-esteem vanishes in the belief of uselessness and that they should not or do not need to continue to exercise their experience of sexuality, negatively impacting their health and $\mathrm{QoL}^{(3)}$.

The uniqueness of the elderly population and the ageing of the Brazilian population, an important phenomenon for our reflection, stimulates the realization of studies on social perception in face of this reality; about coping with ageing by the elderly; and it highlights the possibilities of connections and possible interlocutions between self-image, self-esteem, active sexuality and QoL in ageing. Based on the complexity of the topic, the discussion is justified, as human sexuality is indispensable for the whole of life ${ }^{(4)}$.

\section{Interlocutions and instruments for measuring the connec- tion between sexuality and ageing}

In the bibliographic search, 11 described instruments were found, with the year of its development in the national and international literature. It was found that the questionnaire most used to assess elderly self-esteem is the Rosenberg scale (1965); for the assessment of self-image, the Silhouettes scale by Stunkard et al. (1983) is the one frequently used. It was possible to identify the questionnaire that aims to assess both elderly self-esteem and self-image, proposed by Steglich (1978), considered the most reliable because it has specific validation for elderly Brazilians ${ }^{(2)}$. As for sexuality, several scales were used. Kinsey's (1948) was used to measure human sexuality, emphasizing sexual diversity, as well as the Aging Sexual Attitudes and Knowledge Scale (ASKAS) (1982), validated in Brazil ${ }^{(9)}$. The ASKAS assesses the knowledge and attitude towards the elderly's sexuality, however in an indirect way. The Sexual Satisfaction for Women, SSS-W (2007) (2), also validated in Brazil, helps psychodiagnosis in sexual dysfunctions. Still, regarding elderly sexuality assessment, on individual sexual habits, international literature has three measurement instruments, namely the Perceived Attitudes Toward Sexuality of the Elderly, the Aging and Sexuality Questionnaire, and the Senior Adult Sexuality Scales (2004) $)^{(1)}$. As for QoL assessment, we found the questionnaires World Health Organization Quality of Life 100 (WHOQOL 100) (1995), the World Health Organization Quality of Life Breaf (WHOQOL-Breaf) (1995-1998), and the World Health Organization Quality of Life Old (WHOQOL-Old) (2002 to 2005) ${ }^{(5)}$. The WHOQOL-Old is a specific and validated instrument for the elderly Brazilian population, which assesses the elderly's QoL and personal satisfaction with different aspects of life, and should be applied in conjunction with the WHOQOL-Breaf ${ }^{10)}$.

These 11 instruments identify variables of predominantly psychological and affective components. Such components were expressed in attitudes of approval or disapproval of oneself, physical activities, self-knowledge, personal values, body image, sexuality and reflections on the QoL and corporeality of different population groups and different cultures. We can consider these instruments with limitations and disadvantages of application with elderly individuals.

In this selection, 89 works were found, including articles, theses and books. Of these, 65 were excluded because they did not fit the topic directly and 24 were selected and discussed with the literature. Then, for the presentation of ideas, conjectures and reflections, reflective and conductive axes on the proposal were woven, originating from reflective interpretations and impressions. The interpretations were guided by the understanding of the topic in Brazil and in the world, in its different cultural and social contexts, directed to the Brazilian reality.

\section{Study limitations}

Due to the type of study presented, it is prudent to state that the reflections had some limitations, mainly considering the review of readings with the VHL, LILACS and SciELO, among others, on ageing, self-image, self-esteem, active sexuality, and QoL. There was a shortage of studies that draw a dialogue between these aspects. Even achieving a diversity in the number of instruments, there is a lack of conjunction of components to assess the criteria and the construction of constructs, mainly culturally.

Being constructs, traits, aptitudes or characteristics supposedly existing and abstracted from a variety of behaviors that have psychological significance and verbal fluency ${ }^{(11)}$. Therefore, the adaptation and validity of instruments that do not take into account the complexity of this fact are presented as limitations. These limitations, under certain conditions, favor that the studied variables can only be understood by scores of the correlated tests. Inference developed through test scores is more than the expression of a measurement instrument's value. The is an investigation that permeates the entire process since the elaboration, application, correction and interpretation of results, limiting possible new dimensions when the degree of relationship with other constructs is known. This limitation was one of the most prevalent in our study. Construct validity is the direct way to verify the extent to which the measure corresponds to the theoretical construction of the phenomenon to be measured and not just present other names. The 11 instruments found and various terminologies demonstrate the confused constitutive and operational notion that can reflect on the connection between self-image, self-esteem, active sexuality, and QoL in ageing in an interconnected way.

Instrument validity can be verified by content, criteria, construct, and appearance validity. Thus, the instruments' limitations and disadvantages herein will be considered in the criterion validity and in the construct validity for that population.

\section{Contributions to the health of the elderly population}

There were express limitations due to the lack of interlocutions and instruments for measuring the connection between sexuality and ageing. The study contributes due to its reflective and perspective character for further discussions on coping with ageing, showing the possibilities of connections and possible interlocutions between self-image, self-esteem, active sexuality and QoL in ageing.

\section{FINAL CONSIDERATIONS}

This study has limitations in relation to the aspects discussed so far, which are thought provoking, but still incipient. It points out the need to delineate investigative possibilities that allow to discuss the 
impact on the direction of educational, informational and assistance programs, which contribute to improving the QoL and health of elderly individuals in Brazil. Thus, in this way, subsidize elements for diagnosing needs to be addressed and implementing intervention projects.

The reflections are not intended to end the discussion, data should not be generalized, since considerations may not be related to other instruments due to the sample.

Therefore, the topic about the elderly's health instigates the conduction of new research, especially qualitative, motivating the validation of instruments that deal with sexuality from the perspective of elderly individuals, given the connections and interconnections between self-image, self-esteem, active sexuality, and QoL in ageing. Research on this topic is important to bring about sociocultural change that can support comprehensive care for elderly individuals. The investigation of the factors that interfere with the experience of sexuality of elderly individuals, without stigmas and reprimands, as in this age group, should be encouraged in the scientific field and in social spaces.

\section{ACKNOWLEDGMENTS}

We would like to thank UFU and UFTM for supporting the study.

\section{ERRATUM}

Article "Connections and interlocations between self-image, self-esteem, active sexuality, and quality of life in ageing", with number of DOI: http://dx.doi. org/10.1590/0034-7167-2019-0592, published in the journal Revista Brasileira de Enfermagem, 73(Suppl 3):e20190592, on page 1:

Where to read:

'Universidade Federal de Uberlândia. Uberaba, Minas Gerais, Brazil.

Read:

'Universidade Federal de Uberlândia. Uberlândia, Minas Gerais, Brazil.

\section{REFERENCES}

1. Vieira KFL. Sexualidade e qualidade de vida do idoso: desafios contemporâneos e repercussões psicossociais[Tese][Internet]. João Pessoa. Universidade Federal da Paraíba/Universidade Federal do Rio Grande do Norte 2012 [cited 2019 May 31]. Available from: https://repositorio. ufpb.br/jspui/handle/tede/6908

2. Viscardi AAF, Correia PMS. Questionários de avaliação da autoestima e/ou da autoimagem: vantagens e desvantagens na utilização com idosos. Rev Bras Qual Vida [Internet]. 2017[cited 2019 May 31];9:261-80. Available from: https://periodicos.utfpr.edu.br/rbqv/article/view/5845/4574

3. Feliciano A, Galinha S. Percepções dos idosos sobre a sexualidade em idades avançadas: estudo exploratório. Santarém (PA): Rev UIIPS[Internet]. 2017 [cited 2019 May 31];5(3):160-9. doi: 10.25746/ruiips.v5.i3.14532

4. Vieira KFL, Coutinho MPL, Saraiva ERA. A sexualidade na velhice: representações sociais de idosos frequentadores de um grupo de convivência. Psicol Cien Prof. 2016;36(1):196-209. doi: 10.1590/1982-3703002392013

5. Tavares DMS, Matias TGC, Ferreira PCS, Pegorari MS, Nascimento JS, Paiva MM. Qualidade de vida e autoestima de idosos na comunidade. Ciênc Saúde Coletiva. 2016;21(11):3557-64. doi: 10.1590/1413-812320152111.03032016

6. Uchôa YS, Costa DCA, Silva Jr IAP, Silva STSE, Freitas WMTM, Soares SCS. Sexuality through the eyes of the elderly. Rev Bras Geriatr Gerontol. 2016;19(6):939-49. doi: 10.1590/1981-22562016019.150189

7. Almeida T, Lourenço, ML. Envelhecimento, amor e sexualidade: utopia ou realidade? Rev Bras Geriatr Gerontol. 2007;10(1):101-13. doi: 10.1590/1809-9823.2007.10018

8. Simões R, Moura MM, Moreira WW. Esperando a morte: o corpo idoso institucionalizado. Polêmica. 2016;16(3):49-61. doi: 10.12957/ polemica.2016.25202

9. Viana HB, Guirardello EB, Madruga VA. Texto Contexto Enferm. 2010;19(2):238-45. doi: 10.1590/S0104-07072010000200004

10. Pereira D, Ponte F, Costa E. Preditores das atitudes negativas face ao envelhecimento e face à sexualidade na terceira idade. Anál Psicol. 2018;36(1):31-46. doi: 10.14417/ap.1341

11. Medeiros RKS, Ferreira JMA, Pinto DPSR, Vitor AF, Santos VEP, Barichello E. Pasquali's model of content validation in the Nursing researches . Rev Enf Ref Feb. 2015;4:127-35. doi: 10.12707/RIV14009 